\title{
Extensive loss of translational genes in the structurally dynamic mitochondrial genome of the angiosperm Silene latifolia
}

\author{
Daniel B Sloan ${ }^{*}$, Andrew J Alverson², Helena Štorchová ${ }^{3}$, Jeffrey D Palmer ${ }^{2}$, Douglas R Taylor ${ }^{1}$
}

\begin{abstract}
Background: Mitochondrial gene loss and functional transfer to the nucleus is an ongoing process in many lineages of plants, resulting in substantial variation across species in mitochondrial gene content. The Caryophyllaceae represents one lineage that has experienced a particularly high rate of mitochondrial gene loss relative to other angiosperms.

Results: In this study, we report the first complete mitochondrial genome sequence from a member of this family, Silene latifolia. The genome can be mapped as a 253,413 bp circle, but its structure is complicated by a large repeated region that is present in 6 copies. Active recombination among these copies produces a suite of alternative genome configurations that appear to be at or near "recombinational equilibrium". The genome contains the fewest genes of any angiosperm mitochondrial genome sequenced to date, with intact copies of only 25 of the 41 protein genes inferred to be present in the common ancestor of angiosperms. As observed more broadly in angiosperms, ribosomal proteins have been especially prone to gene loss in the S. latifolia lineage. The genome has also experienced a major reduction in tRNA gene content, including loss of functional tRNAs of both native and chloroplast origin. Even assuming expanded wobble-pairing rules, the mitochondrial genome can support translation of only 17 of the 61 sense codons, which code for only 9 of the 20 amino acids. In addition, genes encoding $18 \mathrm{~S}$ and, especially, $5 \mathrm{~S}$ rRNA exhibit exceptional sequence divergence relative to other plants. Divergence in one region of 185 rRNA appears to be the result of a gene conversion event, in which recombination with a homologous gene of chloroplast origin led to the complete replacement of a helix in this ribosomal RNA.

Conclusions: These findings suggest a markedly expanded role for nuclear gene products in the translation of mitochondrial genes in S. latifolia and raise the possibility of altered selective constraints operating on the mitochondrial translational apparatus in this lineage.
\end{abstract}

\section{Background}

The mitochondrial genomes of flowering plants exhibit a number of characteristics that distinguish them from the mitochondrial genomes of other eukaryotes [1]. They are large and variable in size with ample non-coding content [2], including substantial amounts of "promiscuous" DNA of nuclear and chloroplast origin [3,4] as well as sequences of horizontal origin acquired from the mitochondrial genomes of other land plants $[5,6]$. Angiosperm mitochondrial genomes also contain

\footnotetext{
* Correspondence: dbs4a@virginia.edu

'Department of Biology, University of Virginia, Charlottesville, VA, USA

Full list of author information is available at the end of the article
}

numerous introns, some of which have been split such that the resulting gene fragments must be transcribed separately and then trans-spliced together [7]. Gene expression also relies on extensive C-to- $\mathrm{U}$ (and sometimes U-to-C) RNA editing, in which substitution of specific pyrimidines in the mRNA sequence restores phylogenetically conserved codons [8]. Plant mitochondrial genomes generally experience some of the slowest documented rates of nucleotide substitution $[9,10]$ but are subject to rapid structural evolution [11]. High frequency intra- and intermolecular recombination among large repeated sequences is the rule, generating a heterogeneous pool of genome configurations within a 
single individual [12-14]. The size and complexity of plant mitochondrial genomes, especially when compared with animals and fungi, make them powerful models for exploring the forces affecting eukaryotic genome structure and evolution.

The genomes of plant mitochondria, like any organelle genome, depend on highly integrated functional coordination with the nucleus. For example, translation of mitochondrially-encoded genes requires a mix of nuclear and mitochondrially encoded components. Plant mitochondrial genomes contain genes for their own rRNA subunits as well as for some of the ribosomal proteins and tRNAs required for translation (Figure 1), but many necessary ribosomal protein and tRNA genes are located in the nuclear genome, so their gene products must be imported into the mitochondrion [15]. The tRNA population within plant mitochondria represents a particularly complex assemblage derived from at least 3 anciently divergent classes of genes [15-17]: 1) "native" tRNAs encoded in the mitochondrial genome and inherited from the $\alpha$-proteobacterial progenitor of mitochondria, 2) chloroplast-like tRNAs, which are also encoded in the mitochondrial genome but which were acquired by functional gene transfer from the chloroplast genome during land plant evolution, and 3) nuclear-encoded tRNAs imported from the cytosol.

This mixture of tRNA genes is phylogenetically dynamic. Sequenced plant mitochondrial genomes differ in both the number and the identity of tRNA genes that they contain (Figure 1) $[4,18]$. Likewise, ribosomal protein gene content in the mitochondrial genome is highly variable among plant lineages. The process of mitochondrial gene loss and functional transfer to the nucleus is active and ongoing in plants, and 15 of the 17 protein genes that have been subject to frequent loss across the angiosperm phylogeny encode ribosomal proteins [19-21].

The Caryophyllaceae represents one angiosperm lineage with a relatively high rate of mitochondrial gene loss/transfer. Adams et al. [19] used Southern blots to show that 2 genera from this family (Dianthus and Stellaria) lack most mitochondrial protein genes outside the core set of 24 genes that are nearly universally conserved throughout angiosperms, and we recently reported that 2 species from a third genus (Silene) are similarly reduced in gene content [22]. The genus Silene is of particular interest with respect to mitochondrial genome evolution and transmission [23,24]. This large genus exhibits substantial diversity in breeding system, including a high frequency of gynodioecy (mixed populations of hermaphrodites and females), which is often the result of mitochondrial mutations that induce cytoplasmic male sterility [25]. Furthermore, Silene species differ markedly in mitochondrial mutation rate
[10,26-28] and in the amount of mitochondrial sequence polymorphism that they maintain $[26,27,29,30]$. Previous analyses of Silene mitochondrial genomes, however, have been limited to individual gene sequences.

In this study, we report the complete mitochondrial genome sequence of Silene latifolia, which confirms earlier findings of reduced mitochondrial protein gene content in the Caryophyllaceae. We also found a reduction in tRNA gene content that is unprecedented in plants as well as a major increase in the substitution rate for some rRNA genes. In addition, we use paired-end sequence data and Southern blot hybridizations to analyze the complex structural dynamics of this genome, which are driven by a large recombining repeat sequence that is present in 6 copies. These methods could be used more broadly to explore the complex dynamics of mitochondrial genomes in established plant model systems.

\section{Methods}

\section{Study Species and Plant Material}

Silene latifolia Poir. (Caryophyllaceae) is a short-lived, herbaceous perennial that is widespread in its native Eurasia [31]. Frequently associated with human disturbance, it is also introduced and invasive in other regions, including North America [32]. Like other members of Silene section Elisanthe, S. latifolia has a dioecious breeding system with $\mathrm{XY}$ chromosomal sex determination $[25,33]$.

We grew seeds from a single maternal family in the greenhouse. These seeds were collected by D.R. Sowell from a common garden experiment in Oxford, England, but the maternal plant was derived from seed originally collected on the Apple Orchard Falls Trail in Bedford County, Virginia, USA. A voucher specimen from this family was deposited in the Massey Herbarium at Virginia Polytechnic Institute and State University (D. Sloan \#004). Fifteen weeks after the seeds were sown, we harvested $500 \mathrm{~g}$ of flowers and fresh green leaves from a total of 550 plants.

\section{Mitochondrial DNA Extraction, Sequencing, Assembly, and Finishing}

We followed previously published protocols for plant organelle DNA extraction [34,35], which yielded approximately $4 \mu \mathrm{g}$ of mitochondrial DNA. We confirmed the purity of the DNA by digesting a $100 \mathrm{ng}$ sample with PstI and observing a well-defined electrophoretic banding pattern on an agarose gel.

Library construction, cloning, shotgun sequencing, and genome assembly were performed by the Genome Center at Washington University in St. Louis. The genomic DNA was fragmented using a Hydroshear (Digilab; Holliston, MA), end polished, and run on a $0.8 \%$ agarose 


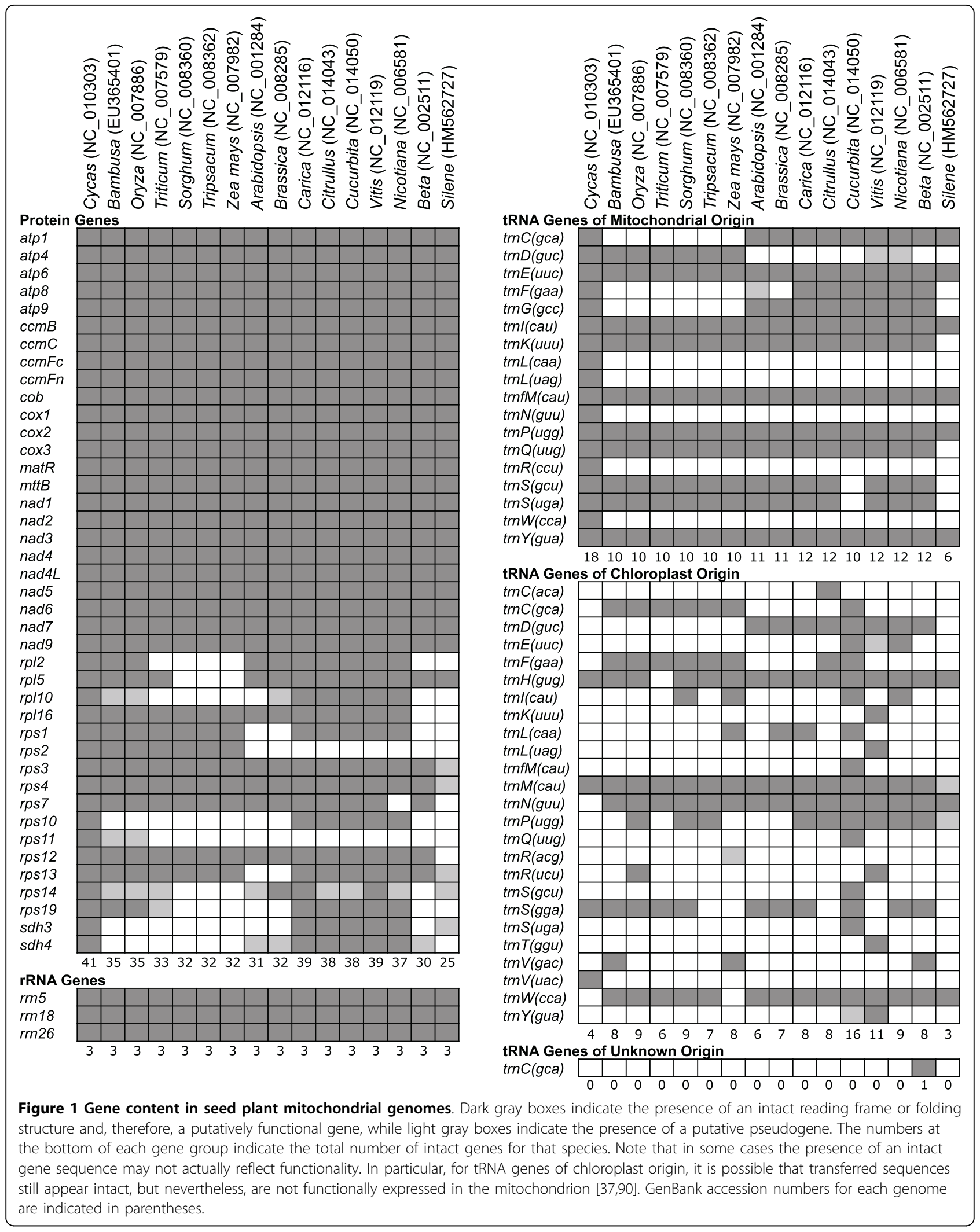


gel. A fraction of that gel corresponding to a 4-6.5 kb size range was excised, purified and ligated into the pSMART vector system (Lucigen; Middleton, WI). After transformation, 2688 subclones were purified, cycle sequenced from both ends with BigDye v3.1 (Applied Biosystems; Foster City, CA), and analyzed on an ABI 3730 capillary sequencer, providing an average of $7 \times$ genome sequence coverage.

Shotgun sequence data were assembled with Phrap followed by manual sorting in Consed to resolve misassemblies [36]. Assembly gaps were closed by sequencing subclones with paired-end reads that mapped to the ends of adjacent contigs. Regions with low quality or single read coverage were augmented by PCR and Sanger sequencing of total cellular DNA.

\section{Genome Annotation}

Protein, rRNA, and tRNA genes as well as regions of chloroplast origin were identified using BLAST and tRNAscan-SE as described previously [37]. Regions that were not annotated as belonging to one of these categories were used to search against the NCBI non-redundant nucleotide and protein databases (nt/nr) with $\operatorname{BLASTN}(\mathrm{r}=5, \mathrm{q}=-4, \mathrm{G}=8, \mathrm{E}=6, \mathrm{~W}=7$, and $\mathrm{e}=$ 0.001) and BLASTX (netblast v2.2.19 default parameters except $\mathrm{e}=0.001)$. Perfectly repeated sequences were identified with REPuter [38]. The annotated genome sequence was deposited in GenBank (HM562727).

\section{Sequence Analysis}

Previous studies have shown substantial variation in substitution rates among mitochondrial genes within the genus Silene [26,28]. To quantify differences in substitution rate, we analyzed individual protein and rRNA genes in a phylogenetic context with PAML v4.1 [39]. For each gene, we included sequences from 18 seed plant species for which complete mitochondrial genome sequences are available. In these analyses, phylogenetic relationships among the species were constrained according to previous studies $[40,41]$. For protein genes, branch lengths were estimated in terms of both synonymous and non-synonymous substitutions per site with the program codeml as described previously [28]. For rRNA genes, branch lengths were estimated in terms of substitutions per site with the program baseml. We employed a K80 (Kimura 2-parameter) model of substitution for rrn5 (5S rRNA) and an HKY model for rrn18 (18S rRNA) and rrn26 (26S rRNA). For all 3 genes, we modeled rate variation among sites with a gamma distribution. These substitution models were chosen based on the results of likelihood ratio tests between pairs of competing models. Because the annotated boundaries of rRNA genes differ slightly across species, we trimmed all sequences to the shortest annotated length.
Our analysis revealed a substantial elevation in substitution rate for rrn5 in S. latifolia. To determine the structural consequences of these substitutions we used the RNAeval program within the Vienna RNA Package v1.8.4 [42] to calculate the free energy of the predicted secondary structure for plant mitochondrial $5 \mathrm{~S}$ rRNA $[43,44]$. To test for selection for conservation of secondary structure in S. latifolia, we generated 10,000 sequences by randomly placing 16 substitutions (the number observed in S. latifolia) into the Beta vulgaris rrn5 sequence. Beta vulgaris was chosen because it is the most closely related species with an available $r r n 5$ sequence, and it appears to have maintained the ancestral sequence of core eudicots. We compared the free energy of the conserved 5S rRNA secondary structure for S. latifolia to the distribution of values from the 10,000 simulated sequences to determine whether the $S$. latifolia structure was more highly conserved than expected by chance.

\section{Southern Blot Hybridizations}

We used Southern blots to assess the existence and relative abundance of alternative genome conformations resulting from intramolecular recombination between large repeated sequences. Total cellular DNA was purified from individual fresh leaves using a sorbitol extraction method [45]. Samples were taken from 2 individuals from each of 2 full-sib families. Each of these families was generated by crossing a female from the family used for genome sequencing with a male from an unrelated family. Between 0.5 and $1 \mu \mathrm{g}$ of genomic DNA was digested with EcoRI (HF enzyme, New England BioLabs), electrophoresed overnight on a $0.9 \%$ agarose gel, and transferred to a positively charged nylon membrane (Roche) by capillary blotting. Two probes were generated to target single copy regions flanking large repeated sequences. The probes correspond to genomic positions 140,389-141,463 nt ("left") and 5636-6500 nt ("right") and were generated with the following PCR primers: LeftF1 5'- AGTCTGCCTTT GTCCGACTG; LeftR1 5'- TCCCCTTGGGGTTCTTA TCT; RightF2 5'-TCTTTCTTTGCGCTTTCGAT; RightR2 5'-CATTGGCCTTTGCTTCCTT. The probes were labeled with digoxigenin (DIG) using Roche's PCR labeling kit. The genomic blots were hybridized in an EasyHyb buffer (Roche) with the DIG-labeled probe at $42^{\circ} \mathrm{C}$ overnight, washed at high stringency $(0.1 \times$ SSC, $65^{\circ} \mathrm{C}$ ), and detected using CDPStar (Roche). An exposure time of 5 to 20 minutes was sufficient to achieve clear bands on ECL film (Kodak). Preliminary data showed that, when amplified directly from genomic DNA, the "right" probe yielded non-specific hybridization, so the PCR fragment was cloned in pGEM T Easy vector (Promega). The resulting plasmid was used as a 
template to generate the probe with the same PCR primers. The "left" probe was amplified directly from genomic DNA.

\section{Results}

\section{Genome Size and Organization}

The sequenced S. latifolia mitochondrial genome can be mapped as a 253,413 bp "master" circle with a total complexity of $244,058 \mathrm{bp}$ if only a single copy of perfectly repeated sequences greater than $100 \mathrm{bp}$ is included (Figure 2). The majority of the repeated sequence in the genome is represented by a $1362 \mathrm{bp}$ "core" repeat sequence that is present in 6 identical copies, all of which are in the same (i.e., direct) orientation relative to each other. Most of the remaining repeated sequence is found in "extensions" of the core repeat. The extensions are identical stretches of sequence between 12 and 1593 bp shared by 2 or more (but not all 6) of the flanking sequences on either the "left" or "right" side of the core repeat (Figure 3). With the exception of this 6-copy repeat and its extensions, the $S$. latifolia mitochondrial genome is relatively devoid of repeated sequences, containing only 2 other repeat families greater than $100 \mathrm{bp}$ (123 bp and $167 \mathrm{bp}$ ). Each of these is a 2-copy repeat.

The master circle depicted in Figure 2 represents only one of many possible genome conformations. No single circle is fully consistent with all the sequencing reads because there are numerous paired-end conflicts, i.e., cases where 2 reads from the same subclone map too far apart or in the wrong orientation. With default filtering settings in Consed, these conflicts are exclusively associated with the large 6-copy repeat sequence, suggesting active intra- and intermolecular recombination among repeats $[13,14]$.

With 6 copies of the core repeat, there are 36 possible pairs of flanking sequences if all core repeats recombine with each other. Of these, 26 pairs are supported by multiple subclones from our shotgun sequence data. The lack of evidence for the remaining 10 flanking pairs could reflect a reduced frequency or complete absence of these recombination products, but it may also be the result of stochastic sampling and/or cloning bias given our relatively low $(7 x)$ sequencing coverage. To distinguish between these possibilities, we first performed (nonquantitative) $\mathrm{PCR}$ with all possible pairwise combinations of primers designed for the left and right single-copy regions that flank each core repeat plus its repeat extensions. We detected all 36 possible flanking sequence pairs in DNA extracted from a single leaf (data not shown). We then utilized Southern blots to assess the relative abundance of the various recombination products and confirm that the results from the PCR experiment were not simply an artefact of PCR-mediated recombination
[46]. We separately hybridized probes representing one "left" single-copy flanking sequence and one "right" single-copy flanking sequence (Figure 3) to genomic DNA digested with EcoRI. In each case, we detected 6 strong bands, corresponding to the expected sizes of the 6 possible recombination products (Figure 4; Additional File 1). All 6 bands are of similar intensity, suggesting that the alternative conformations of the S. latifolia mitochondrial genome exist at relatively equal frequencies. The "right" probe also unexpectedly hybridized to a $1.8 \mathrm{~kb}$ fragment, producing a seventh, fainter band that was present in a subset of the individuals (Figure 4). Studies are ongoing to assess the possibility that this seventh band reflects the existence of sublimons and substoichiometric shifting in S. latifolia $[47,48]$.

\section{Gene Content \\ Protein Genes}

The S. latifolia mitochondrial genome contains intact and putatively functional copies for all 24 of the protein genes that are nearly universally conserved across the large sample of angiosperm mitochondrial genomes examined to date (Figure 1) [19]. In contrast, the genome appears to lack functional copies for most of the 17 other protein genes that were ancestrally present in angiosperm mitochondrial genomes, but which have been subsequently lost, and for the most part, functionally transferred to the nucleus, many times during the course of angiosperm evolution [19,20].

Eleven of these 17 genes have little or no remnant in the genome, while most of the other 6 genes ( $r p l 5, r p s 3$, rps4, rps13, rps14, and sdh3) appear to be pseudogenes. Of this group, only $r p l 5$ is fully intact relative to other angiosperms. It is possible that rps3 and rps 14 are functional, but both of these genes show evidence of degeneration. The first exon (75 bp) of rps3 has been lost, and the much larger second exon (1773 bp) exhibits a substantial 3' extension before the first in-frame stop codon relative to other angiosperms. The 5 ' portion of rps14 is altered by a frameshift mutation that is corrected after 45 bp by a second frameshift indel. The remaining genes either lack substantial regions that are conserved in other angiosperms (rps4) or are truncated by internal stop codons (rps13 and sdh3). Based on these results, we have identified putatively functional genes and pseudogenes in Figure 1, though a more definitive classification will require detailed analysis of gene expression and function. Regardless, it is apparent that the S. latifolia mitochondrial genome has lost a large fraction of the protein genes that were part of the ancestral angiosperm mitochondrial genome.

\section{tRNA Genes}

The S. latifolia mitochondrial genome contains substantially fewer tRNA genes than any angiosperm 


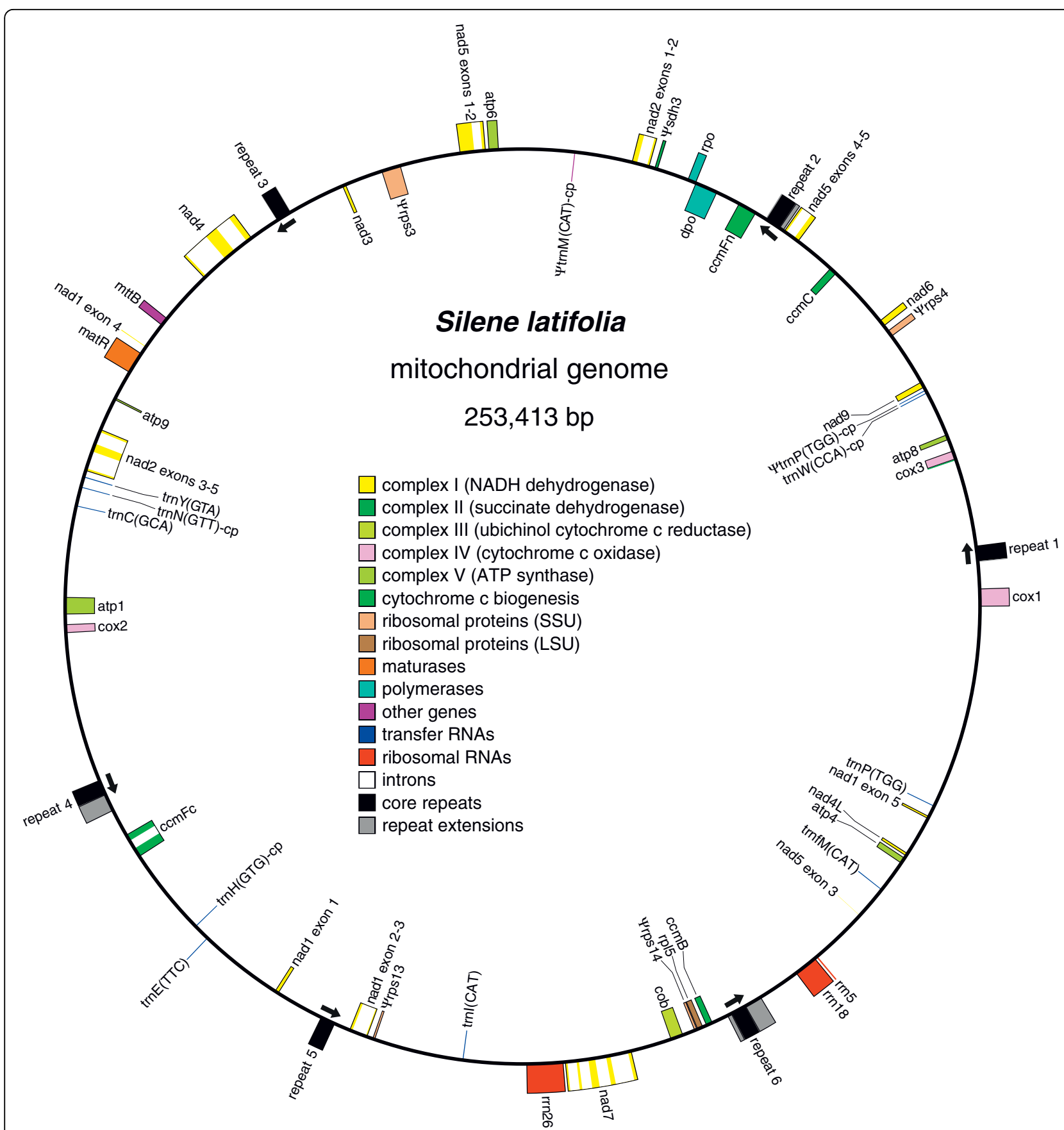

Figure 2 Mitochondrial genome map. One of many possible master circle representations of the Silene latifolia mitochondrial genome (although this does not necessarily reflect the in vivo structure of the genome; see Discussion). Boxes inside and outside the circle correspond to genes on the clockwise and anti-clockwise strand, respectively. Arrows indicate the orientation of repeats as shown in Figure 3. This figure was generated with OGDraw v1.1 [91].

mitochondrial genome sequenced to date. A search of the genome with BLASTn and tRNAscan-SE identified only 11 tRNA genes, and at least 2 of these $(\operatorname{trn} P-c p$ and trnM-cp) are potential pseudogenes based on the presence of multiple substitutions and insertions in their anticodon loops. A third gene (trnfM) shows an elevated substitution rate, but its anticodon and secondary structure appear largely intact (Additional File 2). Five of the 11 genes (including both potential pseudogenes) are of chloroplast origin, representing apparently ancient cpDNA transfers that pre-date the divergence between Silene and Beta. Collectively, the genes encode a set of 


$61 \mathrm{bp}$
$430 \mathrm{bp}$
$36 \mathrm{bp}$
$12^{*} \mathrm{bp}$
$12^{*} \mathrm{bp}$
$430 \mathrm{bp}$

tRNAs that, even after including the potential pseudogenes and assuming expanded wobble pairing rules $[49,50]$, can translate only 17 of the 61 sense codons, encoding only 9 of the 20 amino acids (Table 1). By comparison, mitochondrially-encoded tRNAs in Beta vulgaris (the most closely related species with a complete mitochondrial genome sequence) can potentially recognize 35 codons, encoding 16 amino acids. Therefore, it is likely that an unusually large fraction of the $S$. latifolia mitochondrial tRNA population is encoded in the nuclear genome and imported from the cytosol.

\section{rRNA Genes}

Like other angiosperm mitochondrial genomes, the $S$. latifolia genome contains genes encoding 3 ribosomal RNA species ( $r r n 5, r r n 18$, and $r r n 26)$. Two divergent copies of the rrn5 gene are present, although one is likely non-functional, exhibiting 3 substantial insertions $(7,9$, and $16 \mathrm{bp})$ and multiple substitutions that greatly
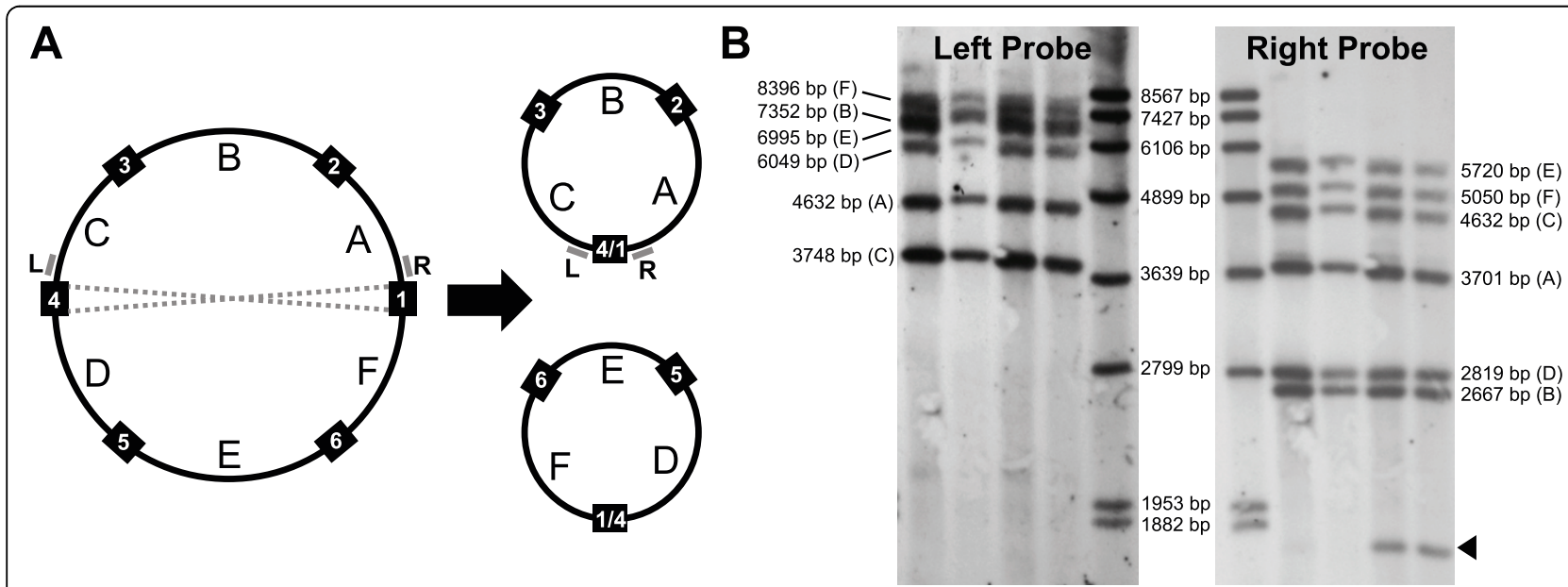

Figure 4 Recombining repeats in the Silene latifolia mitochondrial genome. (A) A stylized version of the master circle undergoing one of many possible recombination events. The black boxes represent the 6-copy repeat with numbering corresponding to Figure 2. The lettered sections represent intervening single-copy regions. The "left" and "right" probes used in Southern blot hybridizations are indicated with small gray bars and labeled $L$ and $R$, respectively. The dotted gray lines indicate a crossover event between repeat copies that produces 2 subgenomic molecules. Given all possible recombination events, each left flanking sequence has the potential to be paired with 6 different right flanking sequences (and vice versa), and therefore, each probe is expected to hybridize to 6 restriction fragments. (B) Southern blot hybridizations with "left" and "right" probes each show 6 strong bands, corresponding to the sizes predicted based on recombination among the 6 large repeats (see Additional File 1 for a more resolved replicate of the "left" probe blot). The left pair of lanes contain DNA samples from one full-sib family, while the right pair contain DNA samples from a second full-sib family. The size standards are indicated by the values between the two blots. The values on either side represent the predicted fragment sizes with the corresponding single-copy flanking sequence noted in parentheses. The black triangle indicates an unexpected $1.8 \mathrm{~kb}$ fragment detected in some but not all individuals with the "right" probe. 
Table 1 Translational capacity of mitochondrially encoded tRNAs in Silene latifolia

\begin{tabular}{|c|c|c|c|c|c|c|c|c|c|c|c|}
\hline UUU & Phe & - & UCU & Ser & - & UAU & Tyr & wobble & UGU & Cys & wobble \\
\hline UUC & Phe & - & UCC & Ser & - & UAC & Tyr & $\operatorname{trnY}$ (gua) & UGC & Cys & $\operatorname{trnC}(g c a)$ \\
\hline UUA & Leu & - & UCA & Ser & - & UAA & * & - & UGA & * & - \\
\hline UUG & Leu & - & UCG & Ser & - & UAG & * & - & UGG & Trp & $\operatorname{trnW}(c c a)-c p$ \\
\hline CUU & Leu & - & CCU & Pro & wobble & $C A U$ & His & wobble & CGU & Arg & - \\
\hline CUC & Leu & - & $\mathrm{CCC}$ & Pro & wobble & CAC & His & $\operatorname{trnH}(g u g)-c p$ & CGU & Arg & - \\
\hline CUA & Leu & - & CCA & Pro & $\operatorname{trn} P(\text { ugg })^{3}$ & CAA & Gln & - & $C G A$ & $\operatorname{Arg}$ & - \\
\hline CUG & Leu & - & CCG & Pro & wobble & CAG & Gln & - & CGG & $\operatorname{Arg}$ & - \\
\hline AUU & Ile & - & $A C U$ & Thr & - & $A A U$ & Asn & wobble & $A G U$ & Ser & - \\
\hline$A \cup C$ & Ile & - & ACC & Thr & - & $A A C$ & Asn & $\operatorname{trnN}(g u u)-c p$ & AGC & Ser & - \\
\hline AUA & Ile & $\operatorname{trnl}(\mathrm{cau})^{1}$ & ACA & Thr & - & AAA & Lys & - & AGA & Arg & - \\
\hline AUG & Met & $\operatorname{trnfM}(\mathrm{cau})^{2}$ & ACG & Thr & - & AAG & Lys & - & AGG & $\operatorname{Arg}$ & - \\
\hline GUU & Val & - & GCU & Ala & - & GAU & Asp & - & GGU & Gly & - \\
\hline GUC & Val & - & GCC & Ala & - & GAC & Asp & - & GGC & Gly & - \\
\hline GUA & Val & - & GCA & Ala & - & GAA & Glu & $\operatorname{trn} E(u u c)$ & GGA & Gly & - \\
\hline GUG & Val & - & GCG & Ala & - & GAG & Glu & wobble & GGG & Gly & - \\
\hline
\end{tabular}

${ }^{1}$ The $\mathrm{C}$ in the first anticodon position of $\operatorname{trnl}(\mathrm{cau})$ is assumed to be post-transcriptionally converted to lysidine, which pairs with $\mathrm{A}$.

${ }^{2}$ trnfM(cau) transfers formylmethionine and therefore is assumed to recognize only the AUG start codon. The genome also contains a gene with homology to the chloroplast trnM gene (which recognizes internal AUG codons), but it has experienced a large expansion in its anticodon loop, making its functionality (and its anticodon) uncertain (Additional File 2).

${ }^{3}$ The genome contains a native $\operatorname{trn} P($ ugg) gene as well as a homolog of the chloroplast trnP(ugg) gene. The chloroplast-derived copy is likely a pseudogene in $S$. latifolia, as it is believed to be in some other angiosperm mitochondrial genomes [90,93]. Its anticodon loop has experienced multiple substitutions, including one that converts the ancestral UGG anticodon to AGG (Additional File 2).

reduce the stability of the widely conserved $5 \mathrm{~S}$ rRNA secondary structure (see below).

\section{Intron and RNA Editing Content}

The S. latifolia mitochondrial genome contains a total of 19 group II introns, 6 of which are trans-spliced. All 19 introns are found in protein genes, and all but one occur in genes that encode subunits of complex I (NADH dehydrogenase). The $S$. latifolia lineage has lost the second nad4 intron and both of the cox2 introns found in other angiosperms [51]. It also lacks the group I intron in $\operatorname{cox} 1$, which has been widely distributed across the angiosperm phylogeny by numerous horizontal transfer events [52]. A previous study identified a total of 287 C-to-U RNA editing sites within the genome's protein genes, which is fewer than typically found in angiosperm mitochondrial genome but substantially more than observed in the rapidly evolving congeners $S$. noctiflora and S. conica [22].

\section{Intergenic Regions}

A BLAST search of intergenic regions from the S. latifolia mitochondrial genome found that $46.2 \mathrm{~kb}(23.1 \%)$ of this sequence exhibits significant similarity to other land plant mitochondrial genomes (after excluding sequences of clear chloroplast origin). Much of this conserved sequence is directly flanking annotated genes and likely represents regulatory elements, UTRs and trans-spliced introns [37]. The genome also contains 2 open reading frames (ORFs) related to the DNA and RNA polymerase genes found on linear mitochondrial plasmids in angiosperms and other eukaryotes [53]. These polymerase genes have also been integrated into the mitochondrial genomes in a number of other angiosperms $[54,55]$.

By searching the complete mitochondrial genome sequence against a collection of diverse chloroplast genomes, we identified a total of $2462 \mathrm{bp}$ of apparent chloroplast origin distributed in 9 fragments ranging in size from 43 to $588 \mathrm{bp}$. The total chloroplast contribution represents $1.0 \%$ of the genome, which is on the low end of the range of approximately 1 to $12 \%$ detected in other sequenced angiosperm mitochondrial genomes $[37,56]$. As found in other angiosperms, the S. latifolia mitochondrial genome also contains numerous sequences of apparent nuclear origin, including many regions with homology to (presumably inactivated) angiosperm transposable elements. Nevertheless, based on our search criteria, more than $143.5 \mathrm{~kb}$ of intergenic sequence (a full $56.6 \%$ of the genome) lacks detectable homology with any DNA or protein sequence in the NCBI $\mathrm{nt} / \mathrm{nr}$ databases.

\section{Nucleotide Composition and Codon Usage}

The S. latifolia mitochondrial genome has a $42.6 \%$ GC content, which is slightly below the range of $42.8 \%$ to $45.2 \%$ observed in other sequenced angiosperm mitochondrial genomes $[37,57]$. The patterns of codon usage in protein genes (Additional File 3) are very similar to other angiosperm mitochondrial genomes [57], despite the significant changes in tRNA gene content in the S. latifolia genome. 


\section{Substitution Rates}

Based on a phylogenetic analysis of 18 complete plant mitochondrial genomes, Silene latifolia consistently shows higher substitution rates than its sister lineage, Beta vulgaris (Figure 5). For the most part, these differences are minor, and the substitution rates in S. latifolia are consistent with the low rates that generally characterize plant mitochondrial genomes $[10,28]$. There are, however, 2 notable outliers with more extreme elevations in substitution rate: the protein gene atp 9 and the putatively functional copy of the ribosomal rRNA gene rrn5 (Figure 6). Elevated substitution rates for atp 9 have previously been reported throughout Silene [28], but this study represents the first analysis of $r r n 5$ in the genus.

Despite their elevated substitution rates, both atp 9 and $r r n 5$ exhibit evidence of purifying selection, suggesting that they are still functionally expressed in the mitochondria. While the observed synonymous substitution rate in atp 9 is more than 5 -fold higher than in any other protein gene in S. latifolia, this is the only gene without a single inferred non-synonymous substitution, suggesting strong purifying selection on amino acid sequence (Figure 6; note that atp9, at $225 \mathrm{nt}$ in length, is the shortest protein gene in the genome). In the case of the ribosomal rRNA gene rrn5 (ca. $111 \mathrm{nt}$ ), 13 of the 16 inferred substitutions occur in loops within the conserved secondary structure (Figure 7) [43,44]. Moreover, the 3 substitutions within helices are structurally conservative. Two of those substitutions compensate for each other by altering both bases in a single pairing, resulting in a $C: G$ to $G: C$ change at positions 27:56 (Figure 6). The third substitution found at a conserved helix position (A-to-G at position 98) should still allow for base pairing (G:U instead of A:U). The one predicted change in secondary structure in S. latifolia results from a T-to-G substitution at position 34 . This position normally represents the first base of the terminal loop on that branch, but the substitution should allow it to pair with $\mathrm{C}_{46}$ and extend the preceding helix (Figure 7). As a result, the predicted secondary structure is slightly more stable in S. latifolia $(\Delta G=-40.80)$ than in other angiosperms (e.g., Beta vulgaris; $\Delta G=-39.16$ ). A simulation test that randomly placed mutations in $r r n 5$ showed that, given the number of substitutions in S. latifolia, the conservation of secondary structure is much stronger than expected by chance $(p<0.0001)$. Therefore, it appears that, despite its elevated substitution rate in $S$. latifolia, rrn5 is still under selection to maintain folding stability. In contrast, a second rrn5 copy in S. latifolia is likely a pseudogene, as it contains 3 insertions as well as 3 nucleotide substitutions that disrupt conserved base pairing in helices $(\Delta G=-17.58)$.

\section{Gene Conversion Between Mitochondrial and Chloroplast Sequences}

The distribution of substitutions contributing to the elevated rrn18 divergence in S. latifolia is noticeably clustered (Figure 8a). One cluster of substitutions is likely the result of a gene conversion event in which a segment of at least $47 \mathrm{bp}$ of $r r n 18$ sequence was converted by a homologous chloroplast rrn16 gene (Figure $8 \mathrm{~b}$ ). The boundaries of this apparent conversion tract correspond precisely to the beginning and end of helix 240 (domain I) in the secondary structure model for $16 \mathrm{~S}$ rRNA in Escherichia coli

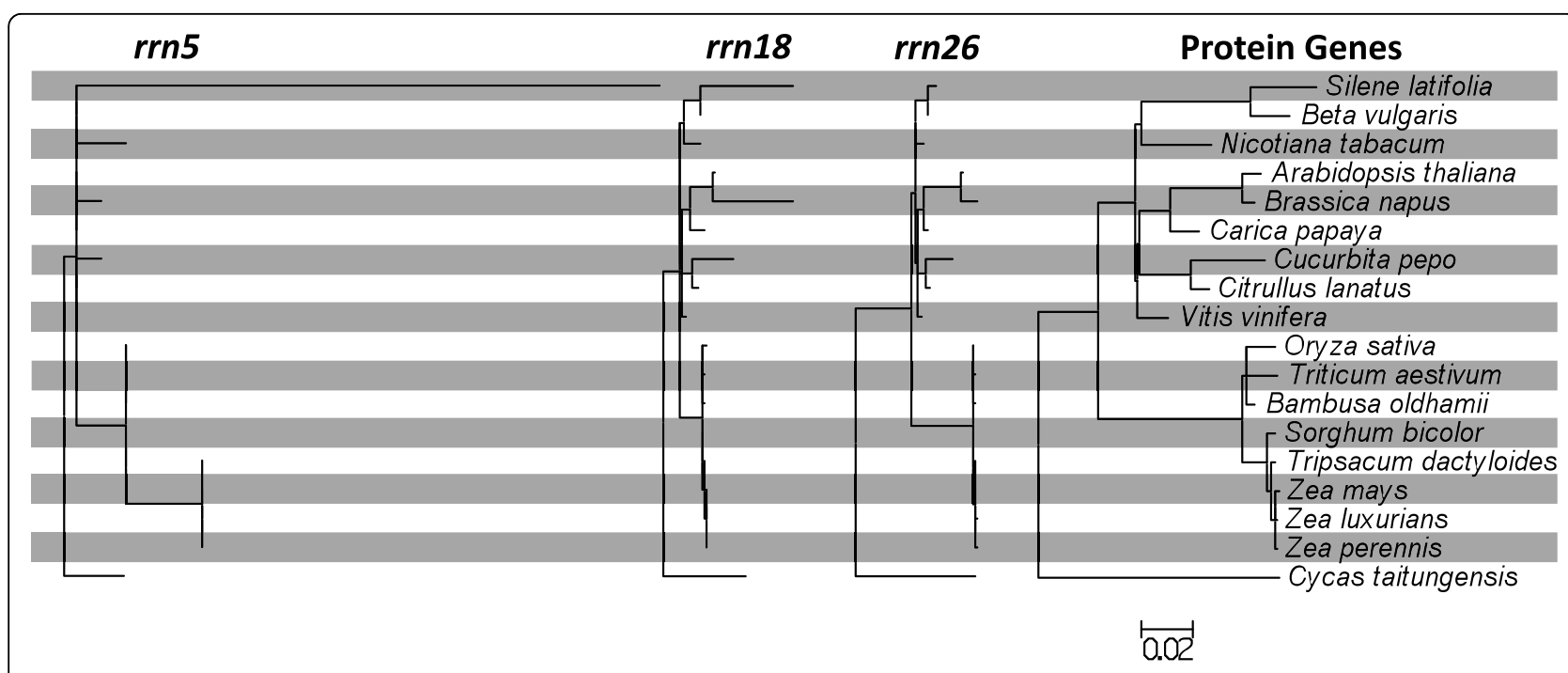

Figure 5 Phylogenetic analysis of substitution rates in seed plant mitochondrial genomes. rRNA gene branch lengths are in terms of substitutions per site, while protein gene branch lengths reflect synonymous substitutions per site based on a concatenated dataset of 25 genes present in the mitochondrial genomes of all 18 species. All analyses used a constrained topology. 


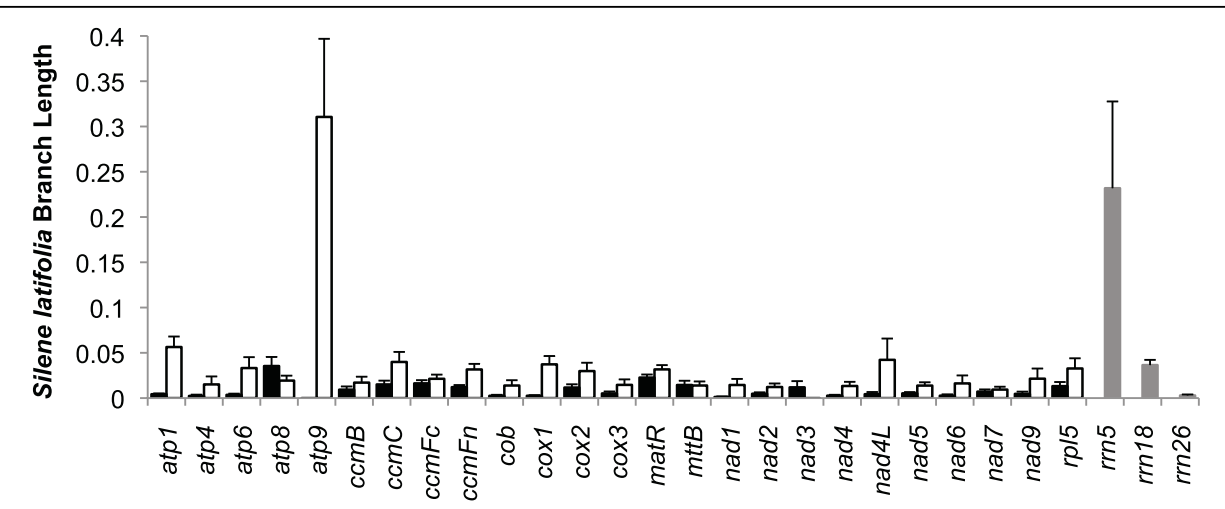

Figure 6 Substitution rate variation among genes in Silene latifolia. Each bar represents the terminal branch length for S. latifolia based on a phylogenetic analysis of 18 land plant species with fully sequenced mitochondrial genomes. For protein genes, branch lengths were estimated in terms of non-synonymous substitutions (black bars) or synonymous substitutions (white bars) per site. For rRNA genes, branch lengths were estimated in terms of substitutions per site (gray bars). Error bars represent standard errors, which were calculated as described by Parkinson et al. [79].

[58]. Therefore, the result of the gene conversion appears to have been a clean exchange of the entirety of this helix. The region appears to have been further modified by multiple substitutions and indels since the conversion event. Evidence of this conversion is also present in S. vulgaris, but not in S. acaulis, indicating that it occurred after the split between the two Silene subgenera but before the divergence of the major lineages in subgenus Behenantha
[28]. We did not find evidence of cpDNA-mediated conversion in any other Silene mitochondrial genes, including the rapidly evolving $r r n 5$ and $a t p 9$ genes.

\section{Discussion}

\section{Mitochondrial Gene Loss}

The vast majority of genes in plant mitochondrial genomes can be placed into one of two functional

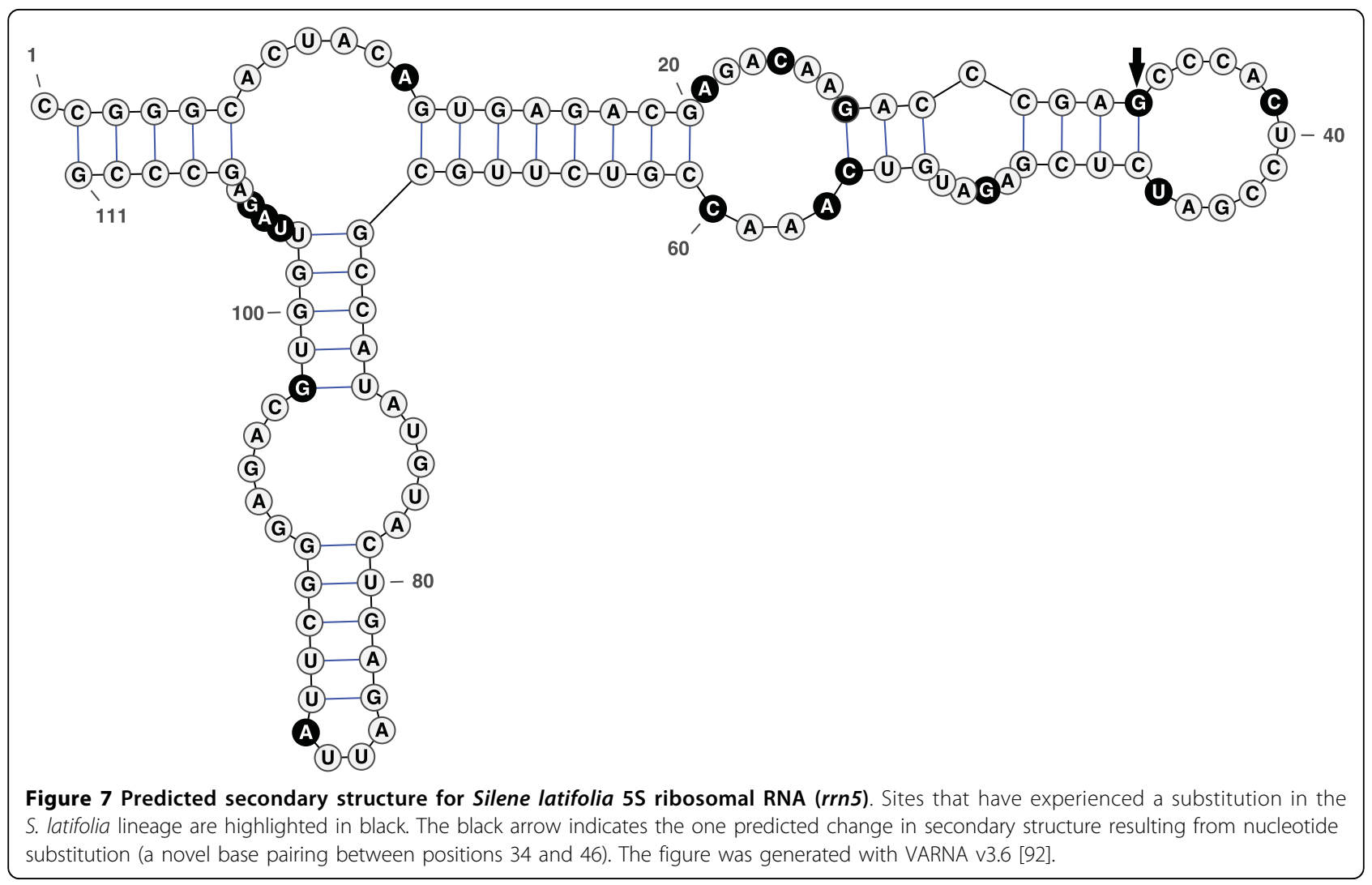




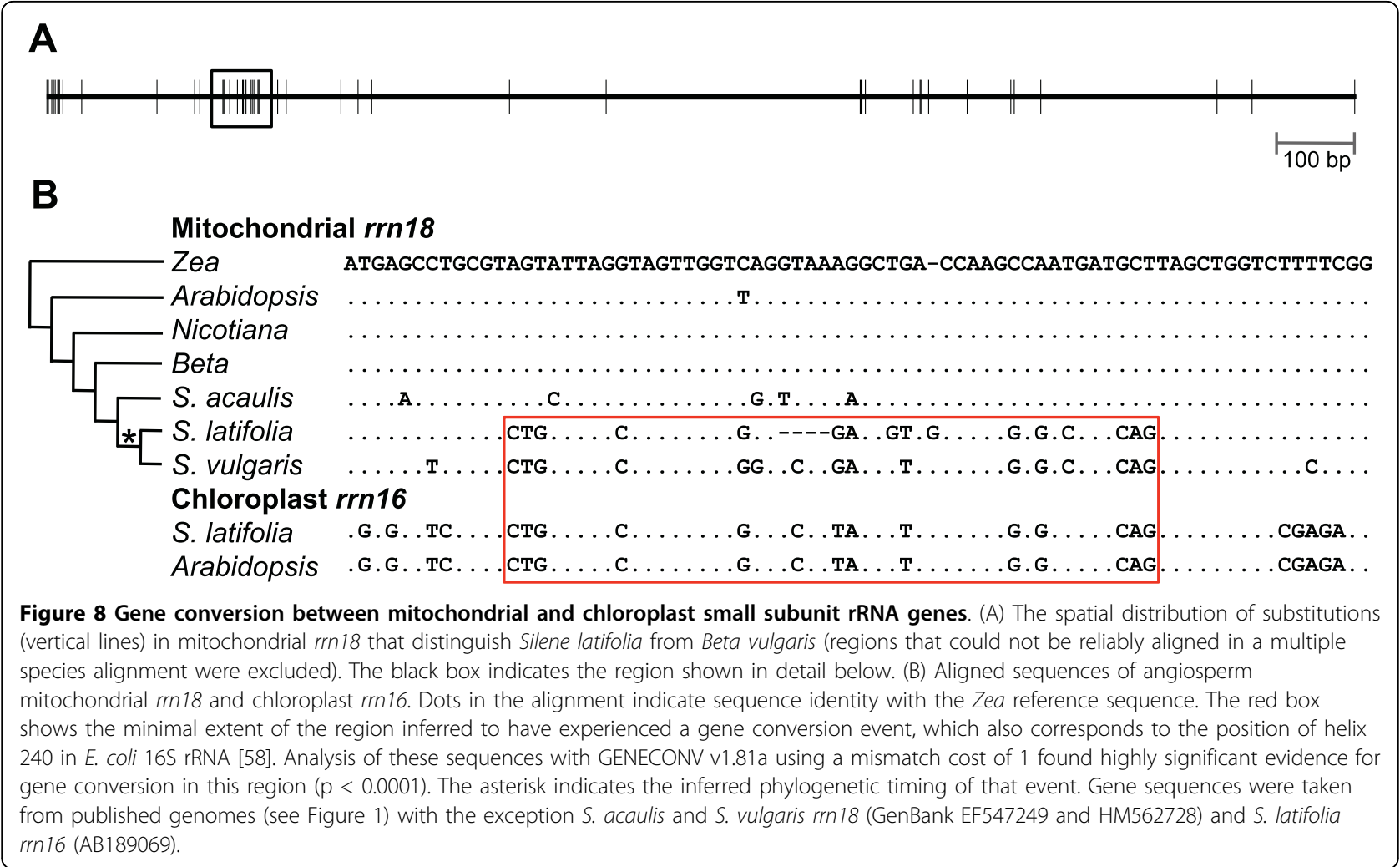

categories: 1) bioenergetics, i.e., oxidative phosphorylation and ATP synthesis ( $a t p, c c m, c o b, c o x, n a d$, and $s d h$ genes) and 2) translational machinery (ribosomal protein, rRNA, and tRNA genes). Analysis of the phylogenetic distribution of protein genes across seed plants has clearly shown that ribosomal proteins are subject to more rapid rates of loss than genes involved in bioenergetics [19]. The complete sequence of the S. latifolia mitochondrial genome provides the first evidence that mitochondrial tRNA genes, another component of the organelle's translational machinery, can also be lost rapidly and in large numbers in plants. This finding is consistent with broader patterns in eukaryotic evolution, as numerous independent lineages have experienced the loss of most or even all of their mitochondriallyencoded tRNAs [59]. The present study also extends earlier work that found reduced protein gene content in 2 other genera in the Caryophyllaceae [19]. The similar reduction in protein gene content in these 3 taxa suggests that much of the observed protein gene loss probably occurred prior to the diversification of this family, although some degree of parallel loss within the family is also possible.

Protein genes that are lost from mitochondrial genomes can experience a variety of fates. For example, the evolutionary history of eukaryotes has been characterized by a massive physical transfer of genes from the mitochondrial genome to the nucleus. This process is ongoing in plants, and there are a number of well-established cases of such endosymbiotic gene transfer that have occurred since the divergence of angiosperms [60-63]. Losses can also occur when a gene is functionally replaced by an anciently divergent homolog $[20,21,64,65]$, and when a protein or even an entire multi-subunit complex is no longer functionally required (e.g., the loss of the NADH dehydrogenase complex I in apicomplexans and at least 2 yeast lineages $[66,67])$. In Silene, an analysis of the $S$. vulgaris transcriptome (unpublished data) revealed evidence of nuclear copies for at least 9 of the protein genes that appear to have been functionally lost from the $S$. latifolia mitochondrial genome.

To the best of our knowledge, a functional transfer of a mitochondrial tRNA gene to the nucleus has never been documented. Instead, mitochondrial tRNA gene loss is typically offset by importing tRNAs of eukaryotic nuclear origin from the cytosol $[17,59]$. Therefore, it is likely that Silene mitochondria import a greatly expanded set of nuclear tRNAs relative to other plantsa prediction that could be tested by purifying and sequencing Silene organelle tRNAs.

In some specific cases, however, more complex evolutionary changes may be required to explain the loss of mitochondrially-encoded tRNAs. For example, in plant 
mitochondria, the function of tRNA-Gln is dependent on coordinated enzymatic processes. Aminoacyl tRNA synthetases play an essential role in translation by matching tRNAs with their corresponding amino acids, but plant organelles generally lack a Gln tRNA synthetase. Instead, tRNA-Gln is typically aminoacylated by a Glu tRNA synthetase followed by a chemical modification (amidation) to convert Glu to Gln [68].

The gene encoding tRNA-Gln $(\operatorname{trn} Q)$ is present in all sequenced seed plant mitochondrial genomes with the exception of S. latifolia. The loss of the mitochondriallyencoded copy of tRNA-Gln in S. latifolia raises several possibilities. First, it is conceivable that aminoacylation and amidation are carried out in the same fashion with an imported cytosolic tRNA-Gln. This may be unlikely, however, because it would require associated changes in tRNA recognition for multiple enzymes. Second, it is possible that, unlike other plants, S. latifolia imports the cytosolic Gln tRNA synthetase into its mitochondria, allowing for direct aminoacylation of an imported tRNAGln without the use of a Glu intermediate. Finally, it is possible that $S$. latifolia has experienced an unprecedented transfer of a functional tRNA gene $(\operatorname{trn} Q)$ from the mitochondrial genome to the nucleus, where it is expressed and its product targeted back to the mitochondria. All of these possibilities should be investigated to better understand the mechanisms involved in the coevolution of organellar and nuclear gene content.

It is intriguing that extensive gene loss in two components of Silene mitochondrial translation machinery has been associated with accelerated evolutionary rates in a third component, rRNA genes. This pattern raises the possibility of a correlated reduction in functional constraint across these 3 translational components. A general relaxation of selection on organelle translation has been observed in cases such as the chloroplasts of nonphotosynthetic plants where the organelle's functional role has been greatly reduced [69]. However, we have no $a$ priori reason to expect relaxed selection on mitochondrial gene expression in Silene, and the distribution of substitutions in rrn5 suggests that its secondary structure is under strong selection to maintain function. Broader comparative and functional analyses would be of value in assessing the extent to which correlated evolutionary pressures act on these 3 components of mitochondrial translation machinery.

An alternative interpretation of our results is that, rather than being lost, certain genes have been functionally retained in the mitochondrial genome but escaped detection by our annotation methods. For example, cryptic genes could result from accelerated rates of evolution or the proliferation of introns and RNA editing sites $[18,70]$. Although these explanations are unlikely given the generally slow rate of plant mtDNA sequence evolution and the trend towards a reduced frequency of introns and RNA editing in Silene [22], they certainly cannot be ruled out. Likewise, it is possible that some of the gene fragments that we have classified as pseudogenes are functional. Mitochondrial tRNAs often exhibit aberrant or non-canonical secondary structures, making detection of genes and the assessment of functionality more difficult $[71,72]$. Under any of these scenarios, however, it is still evident that the S. latifolia lineage has experienced a period of significant evolutionary change in its mitochondrially-encoded translation machinery.

\section{Mitochondrial Substitution Rates and Gene Conversion with Chloroplast Genes}

Given that the divergence between mitochondria (proteobacteria) and chloroplasts (cyanobacteria) spans billions of years of evolution [73], the notion that gene conversion is occurring between their respective genomes is rather astonishing. Nevertheless, examples of conversion between the mitochondrial atp 1 and chloroplast atpA genes have been documented in multiple angiosperm lineages [74]. The S. latifolia mitochondrial genome sequence provides compelling evidence for a similar history of conversion in an rRNA gene. Evidence of recombination between divergent rRNA sequences has also been found in free-living bacteria and archaea [75-77], including one other example of a chimeric proteobacterial/cyanobacterial small subunit rRNA [78].

In all documented cases of apparent conversion between mitochondrial and chloroplast genes, the mitochondrial gene acted as the recipient, which may reflect the propensity of angiosperm mitochondrial genomes to acquire and retain "promiscuous sequences", including those of chloroplast origin. If a conversion event in Silene did result from a copy of chloroplast rrn16 that had been incorporated into the mitochondrial genome, the promiscuous sequence must have been subsequently lost, because it is no longer present in the S. latifolia mitochondrial genome.

The history of gene conversion in S. latifolia rrn18 was readily detectable because the conversion tract (47 to 60 bp in length) introduced a distinct cluster of 14 substitutions (although 2 of these appear to have been obscured by subsequent mutations; Figure 8 ). These changes contributed to an accelerated rrn18 substitution rate in Silene (Figure 5). Although we did not identify other clusters of substitutions that could be readily explained by gene conversion with homologous chloroplast sequence, it is conceivable that more localized conversion events occurred but escaped detection. It would be difficult if not impossible to distinguish conversion events that introduce only 1 or 2 substitutions from de novo point mutations. It has been hypothesized that increases in the frequency of gene conversion with reverse transcribed mitochondrial mRNA ("mutagenic retroprocessing") might explain elevated 
evolutionary rates in some angiosperm mitochondrial genomes [79]. Given the evidence for gene conversion between mitochondrial and chloroplast genes, the role of DNA-mediated conversion between divergent homologs (or even non-homologous sequences that share small regions of similarity) should be investigated as another potential source of mutational input in plant mitochondrial genomes.

\section{Repeats, Recombination, and Genome Structure}

With rare exception [80], the structure of angiosperm mitochondrial genomes is characterized by the presence of large repeated sequences that facilitate intra-and intermolecular recombination [12,14]. These repeats are generally present in 2 or sometimes 3 copies. In this study, we identified an unprecedented 6-copy family of large, actively recombining repeats in the $S$. latifolia mitochondrial genome. Given a repeat family of this size and recombinational activity, there are 120 different possible conformations for the idealized "master circle", which differ in the precise order of the 6 single-copy regions. The genome structure depicted in Figure 2 represents one of these possible conformations. However, the genome organization is much more complex than any single circular representation for at least 2 reasons. First, a 6copy family of recombining repeats will potentially generate hundreds of possible subgenomic circles containing anywhere from 1 to 5 repeat loci, as well as a theoretically infinite number of supergenomic circles through multimerization. Second, plant mitochondrial genomes have been shown to exist in vivo as a complex assemblage of linear, circular and branched molecules [81,82].

As observed in cases of repeat families with lower copy number [12,83-89], our Southern blot hybridizations confirm the co-existence of multiple alternative genome conformations. The similar intensity of each band (Figure 4) suggests that recombination among the repeats is sufficiently frequent that the many possible pairs of flanking sequences occur at relatively equal levels, a condition defined as "recombinational equilibrium" [13]. Moreover, the repeat copies appear to be completely identical in sequence, providing further evidence for a high rate of homogenization through recombination/gene conversion.

For this study, we utilized Southern blots and in silico predictions from a completely sequenced plant mitochondrial genome to provide a semi-quantitative assessment of recombination activity. Extending these methods to other sequenced genomes that differ in the number and size of repeat families could provide valuable comparative data on recombination activity in plant mitochondria. Moreover, the advent of DNA sequencing technologies (e.g., 454 and Illumina) that produce deep sequencing coverage of large span paired-end libraries can provide an opportunity to generate quantitative estimates of the relative abundance of alternative genome conformations.

\section{Conclusions}

Overall, the patterns of gene loss and divergence in the S. latifolia mitochondrial genome suggest a markedly expanded role for nuclear gene products in the translation of mitochondrial genes. Furthermore, the novel, recombinationally active repeat structure of this genome represents a complex elaboration of one of the long list of unique features that distinguish plant mitochondrial genomes. With ongoing efforts to sequence the mitochondrial genomes of other Silene species that differ profoundly in mitochondrial mutation rates and breeding system, the $S$. latifolia mitochondrial genome should provide a valuable comparative model for investigating the evolutionary forces that shape genome organization.

\section{Additional material}

Additional file 1: Southern blot hybridizations.
Additional file 2: Predicted secondary structures of mitochondrially-
encoded tRNAs.
Additional file 3: Summary of codon usage.

\section{Acknowledgements}

We gratefully acknowledge the sequencing work of Lucinda Fulton and the WUSTL Genome Center. We would also like to thank Janis Antonovics, Peter Fields, and two anonymous reviewers for helpful comments on an earlier version of this manuscript. This study was supported by NSF DEB-0808452 (to DBS and DRT), NIH RO1-GM-70612 (to JDP), and MŠMT KONTAKT ME09035 and LC06004 (to HŠ). AJA was supported by an NIH Ruth L. Kirschstein NRSA Postdoctoral Fellowship (1F32GM080079).

\section{Author details \\ ${ }^{1}$ Department of Biology, University of Virginia, Charlottesville, VA, USA. ${ }^{2}$ Department of Biology, Indiana University, Bloomington, IN, USA. ${ }^{3}$ Institute of Experimental Botany, v.v.i, Academy of Sciences of the Czech Republic, Prague 6, Lysolaje, 16502 Czech Republic.}

\section{Authors' contributions}

DBS planned the study, extracted DNA, performed genome finishing and most of the data analysis, and drafted the manuscript. AJA extracted DNA and helped plan the study, analyze the data and draft the manuscript. HŠ performed the Southern blot analysis and helped draft the manuscript. JDP and DRT helped plan the study, analyze the data and draft the manuscript. All authors read and approved the final manuscript.

Received: 1 July 2010 Accepted: 10 September 2010 Published: 10 September 2010

\section{References}

1. Gray MW, Burger G, Lang BF: Mitochondrial evolution. Science 1999, 283(5407):1476-1481.

2. Ward BL, Anderson RS, Bendich AJ: The mitochondrial genome is large and variable in a family of plants (Cucurbitaceae). Cell 1981, 25(3):793-803.

3. Ellis J: Promiscuous DNA-chloroplast genes inside plant mitochondria. Nature 1982, 299(5885):678-679. 
4. Kubo T, Newton $\mathrm{KJ}$ : Angiosperm mitochondrial genomes and mutations. Mitochondrion 2008, 8(1):5-14

5. Richardson $\mathrm{AO}$, Palmer JD: Horizontal gene transfer in plants. J Exp Bot 2007, 58(1):1-9.

6. Bock R: The give-and-take of DNA: horizontal gene transfer in plants. Trends Plant Sci 2010, 15(1):11-22.

7. Malek O, Brennicke A, Knoop V: Evolution of trans-splicing plant mitochondrial introns in pre-Permian times. Proc Natl Acad Sci 1997, 94:553-558.

8. Gray MW, Covello PS: RNA editing in plant mitochondria and chloroplasts. FASEB J 1993, 7(1):64-71.

9. Wolfe $K H$, Li WH, Sharp PM: Rates of nucleotide substitution vary greatly among plant mitochondrial, chloroplast, and nuclear DNAs. Proc Natl Acad Sci 1987, 84(24):9054-9058.

10. Mower JP, Touzet P, Gummow JS, Delph LF, Palmer JD: Extensive variation in synonymous substitution rates in mitochondrial genes of seed plants. BMC Evol Biol 2007, 7(1):135.

11. Palmer JD, Herbon LA: Plant mitochondrial DNA evolves rapidly in structure, but slowly in sequence. J Mol Evol 1988, 28(1-2):87-97.

12. Palmer JD, Shields CR: Tripartite structure of the Brassica campestris mitochondrial genome. Nature 1984, 307:437-440.

13. Lonsdale DM, Brears T, Hodge TP, Melville SE, Rottmann WH: The plant mitochondrial genome: homologous recombination as a mechanism for generating heterogeneity. Philos Trans R Soc Lond B Biol Sci 1988, 319(1193):149-163.

14. Marechal A, Brisson N: Recombination and the maintenance of plant organelle genome stability. New Phytol 2010, 186:299-317.

15. Dietrich A, Small I, Cosset A, Weil JH, Marechal-Drouard L: Editing and import: strategies for providing plant mitochondria with a complete set of functional transfer RNAs. Biochimie 1996, 78(6):518-529.

16. Small I, Akashi K, Chapron A, Dietrich A, Duchene AM, Lancelin D, MaréchalDrouard L, Menand B, Mireau H, Moudden Y: The strange evolutionary history of plant mitochondrial tRNAs and their aminoacyl-tRNA synthetases. J Hered 1999, 90(3):333-337.

17. Glover KE, Spencer DF, Gray MW: Identification and structural characterization of nucleus-encoded transfer RNAs imported into wheat mitochondria. J Biol Chem 2001, 276(1):639-648.

18. Grewe $F$, Viehoever $P$, Weisshaar $B$, Knoop V: A trans-splicing group I intron and tRNA-hyperediting in the mitochondrial genome of the lycophyte Isoetes engelmannii. Nucleic Acids Res 2009, 37(15):5093-5104

19. Adams KL, Qiu YL, Stoutemyer M, Palmer JD: Punctuated evolution of mitochondrial gene content: high and variable rates of mitochondrial gene loss and transfer to the nucleus during angiosperm evolution. Proc Natl Acad Sci 2002, 99(15):9905-9912.

20. Mower JP, Bonen L: Ribosomal protein L10 is encoded in the mitochondrial genome of many land plants and green algae. BMC Evol Biol 2009, 9(1):265.

21. Kubo N, Arimura S: Discovery of the rpl10 gene in diverse plant mitochondrial genomes and its probable replacement by the nuclear gene for chloroplast RPL10 in two lineages of angiosperms. DNA Res 2010, 17(1):1-9.

22. Sloan DB, MacQueen AH, Alverson AJ, Palmer JD, Taylor DR: Extensive loss of RNA editing sites in rapidly evolving Silene mitochondrial genomes: Selection vs. retroprocessing as the driving force. Genetics 2010 185(4):1369-1380.

23. McCauley DE, Bailey MF, Sherman NA, Darnell MZ: Evidence for paternal transmission and heteroplasmy in the mitochondrial genome of Silene vulgaris, a gynodioecious plant. Heredity 2005, 95(1):50-58

24. Bernasconi G, Antonovics J, Biere A, Charlesworth D, Delph LF, Filatov D, Giraud T, Hood ME, Marais GAB, McCauley D: Silene as a model system in ecology and evolution. Heredity 2009, 103:5-14.

25. Desfeux C, Maurice S, Henry JP, Lejeune B, Gouyon PH: Evolution of reproductive systems in the genus Silene. Proc $R$ Soc Lond B 1996, 263(1369):409-414

26. Barr CM, Keller SR, Ingvarsson PK, Sloan DB, Taylor DR: Variation in mutation rate and polymorphism among mitochondrial genes in Silene vulgaris. Mol Biol Evol 2007, 24(8):1783-1791.

27. Sloan DB, Barr CM, Olson MS, Keller SR, Taylor DR: Evolutionary rate variation at multiple levels of biological organization in plant mitochondrial DNA. Mol Biol Evol 2008, 25(2):243-246.
28. Sloan DB, Oxelman B, Rautenberg A, Taylor DR: Phylogenetic analysis of mitochondrial substitution rate variation in the angiosperm tribe Sileneae (Caryophyllaceae). BMC Evol Biol 2009, 9:260.

29. Stadler T, Delph LF: Ancient mitochondrial haplotypes and evidence for intragenic recombination in a gynodioecious plant. Proc Natl Acad Sci USA 2002, 99(18):11730-11735.

30. Touzet $P$, Delph LF: The effect of breeding system on polymorphism in mitochondrial genes of Silene. Genetics 2009, 181(2):631-644.

31. Jalas J, Suominen J: Atlas florae Europaeae. Distribution of vascular plants in Europe. III. Caryophyllaceae. 1987.

32. Taylor DR, Keller SR: Historical range expansion determines the phylogenetic diversity introduced during contemporary species invasion. Evolution 2007, 61(2):334-345.

33. Nicolas M, Marais G, Hykelova V, Janousek B, Laporte V, Vyskot B, Mouchiroud D, Negrutiu I, Charlesworth D, Moneger F: A gradual process of recombination restriction in the evolutionary history of the sex chromosomes in dioecious plants. PLOS Biol 2005, 3(1):47-56.

34. Kolodner R, Tewari KK: Physicochemical characterization of mitochondrial DNA from pea leaves. Proc Natl Acad Sci 1972, 69(7):1830-1834.

35. Palmer JD: Physical and gene mapping of chloroplast DNA from Atriplex triangularis and Cucumis sativa. Nucleic Acids Res 1982, 10(5):1593-1605.

36. Gordon D, Abajian C, Green P: Consed: a graphical tool for sequence finishing. Genome Res 1998, 8(3):195-202.

37. Alverson AJ, Wei X, Rice DW, Stern DB, Barry K, Palmer JD: Insights into the evolution of plant mitochondrial genome size from complete sequences of Citrullus lanatus and Cucurbita pepo (Cucurbitaceae). Mol Biol Evol 2010, 27(6):1436-1448.

38. Kurtz S, Choudhuri JV, Ohlebusch E, Schleiermacher C, Stoye J, Giegerich R, Journals O: REPuter: the manifold applications of repeat analysis on a genomic scale. Nucleic Acids Res 2001, 29(22):4633-4642.

39. Yang Z: PAML 4: Phylogenetic Analysis by Maximum Likelihood. Mol Biol Evol 2007, 24(8):1586-1591.

40. Buckler ES, Holtsford TP: Zea systematics: ribosomal ITS evidence. Mol Biol Evol 1996, 13(4):612-622.

41. Soltis DE, Soltis PS, Chase MW, Mort ME, Albach DC, Zanis M, Savolainen V Hahn WH, Hoot SB, Fay MF: Angiosperm phylogeny inferred from 18S rDNA, rbcL, and atpB sequences. Bot J Linn Soc 2000, 133(4):381-461.

42. Hofacker IL, Fontana W, Stadler PF, Bonhoeffer LS, Tacker M, Schuster P: Fast folding and comparison of RNA secondary structures. Monatshefte für Chemie 1994, 125(2):167-188.

43. Spencer DF, Bonen L, Gray MW: Primary sequence of wheat mitochondrial $5 \mathrm{~S}$ ribosomal ribonucleic acid: functional and evolutionary implications. Biochemistry 1981, 20(14):4022-4029.

44. Brennicke A, Möller S, Blanz PA: The $18 \mathrm{~S}$ and $5 \mathrm{~S}$ ribosomal RNA genes in Oenothera mitochondria: Sequence rearrangments in the $18 \mathrm{~S}$ and $5 \mathrm{~S}$ rRNA genes of higher plants. Mol General Genet 1985, 198(3):404-410

45. Štorchová H, Hrdličková R, Chrtek J Jr, Tetera M, Fitze D, Fehrer J: An improved method of DNA isolation from plants collected in the field and conserved in saturated $\mathrm{NaCl} / \mathrm{CTAB}$ solution. Taxon 2000, 49:79-84

46. Meyerhans A, Vartanian JP, Wain-Hobson S: DNA recombination during PCR. Nucleic Acids Res 1990, 18(7):1687-1691.

47. Small ID, Isaac PG, Leaver CJ: Stoichiometric differences in DNA molecules containing the atpA gene suggest mechanisms for the generation of mitochondrial genome diversity in maize. EMBO J 1987, 6(4):865-869.

48. Arrieta-Montiel MP, Shedge V, Davila J, Christensen AC, Mackenzie SA: Diversity of the Arabidopsis mitochondrial genome occurs via nuclearcontrolled recombination activity. Genetics 2009, 183(4):1261-1268.

49. Crick FH: Codon-anticodon pairing: the wobble hypothesis. $J$ Mol Biol 1966, 19(2):548-555.

50. Cochella L, Green R: Wobble during decoding: more than third-position promiscuity. Nat Struct Mol Biol 2004, 11(12):1160-1162.

51. Joly S, Brouillet L, Bruneau A: Phylogenetic implications of the multiple losses of the mitochondrial coxll.i3 intron in the angiosperms. Int J Plant Sci 2001, 162(2):359-373.

52. Sanchez-Puerta MV, Cho Y, Mower JP, Alverson AJ, Palmer JD: Frequent, phylogenetically local horizontal transfer of the cox 1 group I intron in flowering plant mitochondria. Mol Biol Evol 2008, 25(8):1762-1777.

53. Shutt TE, Gray MW: Bacteriophage origins of mitochondrial replication and transcription proteins. Trends Genet 2006, 22(2):90-95. 
54. Robison MM, Wolyn DJ: A mitochondrial plasmid and plasmid-like RNA and DNA polymerases encoded within the mitochondrial genome of carrot (Daucus carota L.). Curr Genet 2005, 47(1):57-66.

55. Goremykin W, Salamini F, Velasco R, Viola R: Mitochondrial DNA of Vitis vinifera and the issue of rampant horizontal gene transfer. Mol Biol Evol 2009, 26(1):99-110

56. Kubo T, Mikami T: Organization and variation of angiosperm mitochondrial genome. Physiol Plantarum 2007, 129(1):6-13.

57. Sloan DB, Taylor DR: Testing for selection on synonymous sites in plant mitochondrial DNA: the role of codon bias and RNA editing. J Mol Evol 2010, 70:479-491.

58. Cannone JJ, Subramanian S, Schnare MN, Collett JR, D'Souza LM, Du Y, Feng B, Lin N, Madabusi LV, Müller KM: The Comparative RNA Web (CRW) Site: an online database of comparative sequence and structure information for ribosomal, intron, and other RNAs. BMC Bioinformatics 2002, 3:2.

59. Gray MW, Lang BF, Cedergren R, Golding GB, Lemieux C, Sankoff D, Turmel M, Brossard N, Delage E, Littlejohn TG, Plante I, Rioux P, SaintLouis D, Zhu Y, Burger G: Genome structure and gene content in protist mitochondrial DNAs. Nucleic Acids Res 1998, 26(4):865-878.

60. Nugent JM, Palmer JD: RNA-mediated transfer of the gene coxll from the mitochondrion to the nucleus during flowering plant evolution. Cell 1991, 66(3):473-481.

61. Kubo N, Harada K, Hirai A, Kadowaki K: A single nuclear transcript encoding mitochondrial RPS14 and SDHB of rice is processed by alternative splicing: common use of the same mitochondrial targeting signal for different proteins. Proc Natl Acad Sci 1999, 96(16):9207-9211.

62. Adams KL, Daley DO, Qiu YL, Whelan J, Palmer JD: Repeated, recent and diverse transfers of a mitochondrial gene to the nucleus in flowering plants. Nature 2000, 408(6810):354-357.

63. Liu SL, Zhuang Y, Zhang P, Adams KL: Comparative analysis of structural diversity and sequence evolution in plant mitochondrial genes transferred to the nucleus. Mol Biol Evol 2009, 26(4):875-891

64. Adams KL, Daley DO, Whelan J, Palmer JD: Genes for two mitochondrial ribosomal proteins in flowering plants are derived from their chloroplast or cytosolic counterparts. Plant Cell 2002, 14(4):931-943.

65. Mollier P, Hoffmann B, Debast C, Small I: The gene encoding Arabidopsis thaliana mitochondrial ribosomal protein $\mathrm{S} 13$ is a recent duplication of the gene encoding plastid S13. Curr Genet 2002, 40(6):405-409.

66. Paquin B, Laforest MJ, Forget L, Roewer I, Wang Z, Longcore J, Lang BF: The fungal mitochondrial genome project: evolution of fungal mitochondrial genomes and their gene expression. Curr Genet 1997، 31(5):380-395.

67. Gardner MJ, Hall N, Fung E, White O, Berriman M, Hyman RW, Carlton JM, Pain A, Nelson KE, Bowman S, Paulsen IT, James K, Eisen JA, Rutherford K, Salzberg SL, Craig A, Kyes S, Chan MS, Nene V, Shallom SJ, Suh B, Peterson J, Angiuoli S, Pertea M, Allen J, Selengut J, Haft D, Mather MW, Vaidya AB, Martin DM, Fairlamb AH, Fraunholz MJ, Roos DS, Ralph SA, McFadden Gl, Cummings LM, Subramanian GM, Mungall C, Venter JC, Carucci DJ, Hoffman SL, Newbold C, Davis RW, Fraser CM, Barrell B: Genome sequence of the human malaria parasite Plasmodium falciparum. Nature 2002, 419(6906):498-511.

68. Pujol C, Bailly M, Kern D, Marechal-Drouard L, Becker H, Duchene AM: Dualtargeted tRNA-dependent amidotransferase ensures both mitochondrial and chloroplastic GIn-tRNAGIn synthesis in plants. Proc Natl Acad Sci 2008, 105(17):6481-6485.

69. Wolfe KH, Morden CW, Ems SC, Palmer JD: Rapid evolution of the plastid translational apparatus in a nonphotosynthetic plant: loss or accelerated sequence evolution of tRNA and ribosomal protein genes. J Mol Evol 1992, 35(4):304-317.

70. Feagin JE, Abraham JM, Stuart K: Extensive editing of the cytochrome $c$ oxidase III transcript in Trypanosoma brucei. Cell 1988, 53(3):413-422.

71. Okimoto R, Wolstenholme DR: A set of tRNAs that lack either the T psi C arm or the dihydrouridine arm: towards a minimal tRNA adaptor. EMBO J 1990, 9(10):3405-3411.

72. Schnare MN, Greenwood SJ, Gray MW: Primary sequence and posttranscriptional modification pattern of an unusual mitochondrial tRNA (Met) from Tetrahymena pyriformis. FEBS Lett 1995, 362(1):24-28.

73. Sheridan PP, Freeman KH, Brenchley JE: Estimated minimal divergence times of the major bacterial and archaeal phyla. Geomicrobiol I 2003, 20(1):1-14.
74. Hao W, Palmer JD: Fine-scale mergers of chloroplast and mitochondrial genes create functional, transcompartmentally chimeric mitochondrial genes. Proc Natl Acad Sci 2009, 106(39):16728-16733.

75. Parker MA: Case of localized recombination in 23S rRNA genes from divergent Bradyrhizobium lineages associated with neotropical legumes. Appl Environ Microbiol 2001, 67(5):2076-2082.

76. Schouls $L M$, Schot CS, Jacobs JA: Horizontal transfer of segments of the 16S rRNA genes between species of the Streptococcus anginosus group. J Bacteriol 2003, 185(24):7241-7246.

77. Boucher Y, Douady CJ, Sharma AK, Kamekura M, Doolittle WF: Intragenomic heterogeneity and intergenomic recombination among haloarchaeal rRNA genes. J Bacteriol 2004, 186(12):3980-3990.

78. Miller SR, Augustine S, Olson TL, Blankenship RE, Selker J, Wood AM: Discovery of a free-living chlorophyll d-producing cyanobacterium with a hybrid proteobacterial/cyanobacterial small-subunit rRNA gene. Proc Natl Acad Sci 2005, 102(3):850-855.

79. Parkinson CL, Mower JP, Qiu YL, Shirk AJ, Song K, Young ND, DePamphilis CW, Palmer JD: Multiple major increases and decreases in mitochondrial substitution rates in the plant family Geraniaceae. BMC Evol Biol 2005, 5:73.

80. Palmer JD, Herbon LA: Unicircular structure of the Brassica hirta mitochondrial genome. Curr Genet 1987, 11(6-7):565-570.

81. Oldenburg DJ, Bendich AJ: Size and Structure of Replicating Mitochondrial DNA in Cultured Tobacco Cells. Plant Cell 1996, 8(3):447-461.

82. Backert S, Borner T: Phage T4-like intermediates of DNA replication and recombination in the mitochondria of the higher plant Chenopodium album (L.). Curr Genet 2000, 37(5):304-314.

83. Lonsdale DM, Hodge TP, Fauron CMR, Flavell RB: A predicted structure for the mitochondrial genome from the fertile cytoplasm of maize. In Plant molecular biology: UCLA symposia on Molecular and Cellular Biology, New Series. Edited by: Goldberg RB. New York: AR Liss; 1983:12:445-456.

84. Stern DB, Palmer JD: Recombination sequences in plant mitochondrial genomes: diversity and homologies to known mitochondrial genes. Nucleic Acids Res 1984, 12(15):6141-6157.

85. Palmer JD, Herbon LA: Tricircular mitochondrial genomes of Brassica and Raphanus: reversal of repeat configurations by inversion. Nucleic Acids Res 1986, 14(24):9755-9764.

86. Stern DB, Palmer JD: Tripartite mitochondrial genome of spinach: physical structure, mitochondrial gene mapping, and locations of transposed chloroplast DNA sequences. Nucleic Acids Res 1986, 14(14):5651-5666.

87. Palmer JD: Intraspecific variation and multicircularity in Brassica mitochondrial DNAs. Genetics 1988, 118(2):341-351.

88. Siculella L, Palmer JD: Physical and gene organization of mitochondrial DNA in fertile and male sterile sunflower. CMS-associated alterations in structure and transcription of the atpA gene. Nucleic Acids Res 1988, 16(9):3787-3799.

89. Folkerts O, Hanson MR: Three copies of a single recombination repeat occur on the $443 \mathrm{~kb}$ master circle of the Petunia hybrida 370 mitochondrial genome. Nucleic Acids Res 1989, 17(18):7345-7357.

90. Leon $\mathrm{P}$, Walbot $\mathrm{V}$, Bedinger $\mathrm{P}$ : Molecular analysis of the linear $2.3 \mathrm{~kb}$ plasmid of maize mitochondria: apparent capture of tRNA genes. Nucleic Acids Res 1989, 17(11):4089-4099.

91. Lohse M, Drechsel O, Bock R: OrganellarGenomeDRAW (OGDRAW): a tool for the easy generation of high-quality custom graphical maps of plastid and mitochondrial genomes. Curr Genet 2007, 52(5-6):267-274.

92. Darty K, Denise A, Ponty Y: VARNA: Interactive drawing and editing of the RNA secondary structure. Bioinformatics 2009, 25(15):1974-1975.

93. Placido A, Damiano F, Losacco M, Rainaldi G, De Benedetto C, Gallerani R: Variable structures of promoters regulating transcription of $\mathrm{cp}$-like tRNA genes and of some native genes on the sunflower mitochondrial genome. Gene 2006, 371(1):93-101.

doi:10.1186/1471-2148-10-274

Cite this article as: Sloan et al:: Extensive loss of translational genes in the structurally dynamic mitochondrial genome of the angiosperm Silene latifolia. BMC Evolutionary Biology 2010 10:274. 